\title{
Study on the View of Life and Death of Zhou Dynasty from Bronze
}

\section{Inscriptions}

\author{
Xiuli Wang ${ }^{1}$ \\ ${ }^{1}$ school of literature and law , Sichuan Agricultural University, Ya'an, Sichuan, 625014 \\ 346591653@163.com
}

KEYWORDS: Inscriptions; Zhou; View of Life and Death

\begin{abstract}
Life and death of human culture is an important proposition concerns, Based on the bronze inscriptions terminology investigation, and according to the parameters of the literature handed down, people interpret Zhou profound life experience and psychological feelings, respect for life, well-being and longevity desire, treat death constitute a rational conception of death people Zhou profound ethical connotations. At the same time, from the simple pursuit of life lingering endless, craving to taste Fluke, Corning, and then hope hospice unharmed after Ling, Zhou also shows the concept of human development and changes of life and death.
\end{abstract}

\section{Introduction}

The ultimate question of life and death issue has been a concern of mankind, but also an important part of Chinese Traditional Ethics, how to treat life and death, reflects the people for the meaning of life and awareness of the value. Originally illness and death is a natural law of life, but people as rational political animal, a matter of life and death to produce a variety of ideas and imagination, during which contains a beautiful fantasy and realistic thinking. This article describes the aid of bronze inscriptions, combined with inscriptions relating to the life and death wish good fortune terminology of expedition to explore the changes of people's life and death Zhou wisdom and ideas of life and death.

\section{Prayer for Longevity Eternal Life - Long Length of Life}

"Book • fan":. "Five, one said Shou, second rich, third is Corning, good morals Yau Si Yue, Wu Yue Dynasty end life" "Five" into "life" in first place, Zhu Xi "book set Biography "said:" people can enjoy life and then all blessing, it is the first life, "' life "as the root of all happiness, human life depends on it as the continuation of its greatest happiness, hope and longevity of people since ancient times is the desire to pray. longevity is Zhou bronze inscriptions, the most common prayer language. In the bronze inscriptions before I wish good fortune parlance, pray longevity with speech or prayer alone as the content, or placed all $\mathrm{Gu}$ speech, which reflects the Zhou people's attention and desire for longevity.

Initially, for life, the early Western Zhou people just from a macro perspective on the pursuit of endless lingering, lifeline forever. Such as:

Mai Fang Zun: "Only the emperor off in the provision of wheat cast Hou, Sun its final death forever."

"Release name • funeral release system": "Ultimately, do also." "Singer • Language Week": "Secretary ADPL solitary end" Wei Zhao Note:. "Eventually, die", "end" to "end life. "the 
province," no end "is" life without end. " And the late Western Zhou Dynasty and the Spring and Autumn Period variety of names of specific prayers term longevity compared early Western Zhou prayer speech was relatively general and relatively simple.

After the late Western Zhou Dynasty, pray for longevity terminology gradually enriched this area shows that a well-developed system of Chinese vocabulary, it also shows the Zhou Dynasty to life longevity rational knowledge become increasingly clear. Such as:

Cai Ji Gui: "With Gai Mei Ting, Chuo York, never make, Mi Jue Health, Ling end." (4198 integrated mid-Western Zhou)

"Mei Ting" is the bronze inscriptions are very common with speech, Qin people think when "Mei Ting" is the old man born on the eyebrow hairs, who is one sign of longevity. "The Book of Songs • July": "For this liquor to Jie-Mei Ting." Biography of Mao: "Mei Ting, Mei cents also." And "Release name • Explanation of seniority," says: "90 said back, or say yellow Gou, or say Hu Gou, frozen pear or say, or say teeth, or said Mei Ting. "Zhou people prayer" Huang Gou "' Mei Ting "," Shou Gou "although the meaning longevity, but also clearly shows that have recognized and the recipient of a natural phenomenon of aging. Xu Zhongshu says: "Where this life said the old sign, are all people of physiological aging as a natural phenomenon pray obvious that most people's thinking, not the reality of the scope of ideal realm where everything (as long as the longevity. paradise area is said) are no more. qualities of Chinese Confucian philosophy of the cover also. "

From the beginning of the late Western Zhou Dynasty, including the entire Spring and Autumn Period, the ancients pray for longevity desire more intense by praying "Mei Ting", "Huang Gou" to pray "old hard" and even to "old life no dead." Especially in the Department of bronze inscriptions Qi Spring and Autumn Period, the expression "old hard", "no death" with more remarks, such as:

Qida slaughter unto the Father disk: "Taiwan (to) Chi Mei Ting, Ling life, difficult old." The Shi Ginger first set: "With Chi Mei Ting, difficult old Shi Jia is Paul."

Qihou Bo: "pray for life with no old dead, Paul brothers." This is closely linked with the then social and cultural background of $\mathrm{Qi}, \mathrm{Xu}$ Zhongshu that such language speech production is affected by the Oriental influence was prevalent long as the longevity of say. Zhou people from prayer "old life" to pray "difficult old", as reflected in its longevity psychological desire is essentially different. Xu Zhongshu said: "pray for the old hard and pray tho old, during which real great the difference pray tho old is imperative yellow Gou yellow hair Abutment child tooth Zhu Zheng Qi old hard, then pray no such Zhu Zheng old hard of... Italy can "Zi • Grandmaster" 'son of older men and the color if Ruzi' solution, the elderly and the color if Ruzi, that old hard also. " imperative" no death "that pray immortality, than Inscription common prayer "old life," pray "difficult old" more strongly expressed desire longevity. This kind of "old hard", "no death" of thought became the yin and yang alchemist pursuit of the ideological roots of immortality.

Take Deng Ding: "no life of their brow, Yang's warranty." Wang Sunshou earthenware vessel: "The eyebrow boundless life, no period of years." T my father Gui: "pray with the old boundless life." Inscriptions by "free period" of the speech who are inclined to Spring and Autumn Period, a late or early Warring States period. "None of the" often associated with other longevity prayer together with the use of speech. Such as: Mei Ting no period; no period of years; the old life no period. Time endless words "free period" from the time the longitudinal axis of the permanent expression of life and longevity of our ancestors, descendants of generations of desire. Boundless, popular in the late Western Zhou Dynasty and the Spring and Autumn Period Inscription in, and "Mei Ting", "Yong Ming" "years" and longevity together using speech, made its borderless, endless meaning. "No Borders" from space horizontal line expresses a prayer immortal bliss Fortress desire. "No period" and "No Borders", from the time and space to complete the Zhou Dynasty expression 
longevity life forever, a lot of bliss, desire stretches descendants mission. Appears popular with these two words is reflected in the Spring and Autumn Period immortal ideological vocabulary of the field, also shows in the Spring and Autumn Period of ancient words have the choice and use of temporal ideas.

\section{Prayer for Happiness and Health - the Pursuit of Life Width}

Zhou People do not like abstract life, Zhou's conception of death tend to reflect a material nature, life practice, Zhou Dynasty is committed to the well-being of food and clothing, is committed to longevity. "Said the text display unit": "Fu, Yuya." "Book of Rites Festival reunification": "Fu who also prepared" Zheng Xuan Note:. "The so-called blessing the world who are affected by Youzhu spirits of that so-called Sage Fu who said that that was the name of the Dashun also. "' Fu "is a general term concept, refers to all suffered and protect, blessing Jo. Such as:

Fang Jue for respect: "At first glance Jue Mu Mu Wen Zukao Zun Yi Bao, which used to enjoy Suye Jue bulk, which with Gai Yongfu."

Liang its pot: "pray with more happiness, Mei Ting, Wing order no end." "Yongfu" means God-given blessing of rain, and the language is now forever in Fluke's often said similar. "Dover" Words are numerous and well-being of broad, referring to God, ancestral gods bestowed various people happy, including the "Book • fan" rich in listed life, Corning, Yau Good German, test end life, etc. means security body, in life, Paul Lee and other great blessings. Classics handed down common "multi-fu" word, "The Book of Songs • Daya • King Wen": "never made with life, hope for the best." "• Xiaoya Mary Rose": "God hanging men, Yi Er Duofu. "

classics as "Paul", "Paul," the intention of salary. "Little Ya • Gu release": "Pass, Tatsuya" The idea was to pass. "Book of Rites • appointed justice": "Fu Yin side of the letter also." Brief Account sparse:. "Of who's name was also through" "Lu Tong" is accessible illustrious salary. Xu Zhongshu said: "Mastery read into the next travel pass, pass That was Paul to this language and Buddhism, the Senior Salaries also." in the late Western Zhou Bronze in the "Flow" adding who refers blessings and riches. Such as:

History maker:. "Chase with (fu) "Through, Zhou Gu common speech late inscriptions, and "health", "Tuen right", "Chuo York", "Yong Order", "Tuen Lu", "Mei Ting", " end" and so tied. Such as:

Liang its bell: "pray with Gai Kang Tuen right Chuo York, through." Kang, "Ya • Gu release": "Ann," "music also," "too quiet." Ning, "Ya • Gu release":. "Ann," Zhou people pray to get "Corning" First pray for peace pleasure, no disease, no trouble, and then extended abstract atmosphere of stability and harmony. From the popular time to read, pray Corning's speech mostly focused on the late Western Zhou Dynasty and the Spring and Autumn Period. Ideology and culture in this period of rapid social development stage, the rulers in their own lives being of concern, but also began to witness peace and harmony of the whole social environment, not only want to own physical well-being, but also want to be able to rule long-term stability. Such as:

Poor country: "Let the state cover of tripod kettle quiet peace."'Security", "rather" mutual training common. "Book • Yu-mo":. "Wild exhaustive Yin, IMC Xianning" Lu Deming Explanation: "Ning, Ann." "Selected Works • Hill late <and the Uncle of the book" ".." World peace "Lui to note:" An ., Ning also "' Ya • Gu release under ":" Ning, Ann. "criminal Bing Shu:" Ning, Ann are also well-being. "' security "," rather "synonymy means peace and stability. "Zhuangzi - the world": "May the peace of the world, to the people living life." Modern Chinese "peaceful" setting is juxtaposed compound word. 


\section{Prayer for Die in Natural Death - the Courage to Face Death}

That so-called hospice "Book • fan" "Five" and "Dynasty end life." Test who in old age, the end of life is the end of life. Therefore, "Dynasty end life" means longevity and hospice later years, which is what we now call the dead. "Dynasty end life" is one of "Five," "Book" in the traditional concept of hospice is a manifestation of the old life and blessing. What is hospice? "Book • fan" "Dynasty end life," Kong Anguo Biography:. "Each life into its final length of the self, not cross-yao" This is Zhou rulers pray for a blessing. Bronze pray in the language of old age hospice speech illustrates Zongzhou people thought, and that human beings can not live forever, pray for those "old hard", "Do not die" of the speech is just their good wishes nothing more. Both pray and pray for longevity hospice, indicating Zhou Dynasty "Knowing Fate" open-minded mentality.

Although Zhou people desire to live forever, but in the end could not resist the natural laws of human illness and death, so pray in the Zhou Dynasty, "Mei Ting", "Huang Gou", "Yong Ming", while also pray for hospice later years, such as Chi Gai " Yayoi "," Ling end "," Yong finally Kat "," Ling Ling complex. " From the inscriptions corpus, the longevity remarks pray pray more in the hospice of speech Fluke, longevity after. Such as:

Cai Ji Gui: "With Gai Mei Ting, Chuo York, never make, Mi Jue Health, Ling end." Bell: "that (award) Lu Yu Tuen, never make, Mei Ting, Ling end." (Integrated 247 mid-Western Zhou)

Well Zhong: "Ke Jue Germany, was with Tun Lu, Yong finally Kyrgyzstan." The Shi Ginger first set: "It it hee hee, no men and women of at eventually died, descendants forever."

Winter, mainly popular in the Western Zhou Dynasty in the late evening to the early years. From the use of point of view, inscriptions "Ling final" often put longevity final speech, made by the days of Mary Help of Christians to hospice, or prayer in the day, in order to achieve hospice. "Ling finally" that the literature of the "final order", "Ling", "order" ancient tones belong to the parent farming Characters can be connected. "The Book of Songs • Daya • both drunk": "Zhao Ming has financial, Gaolangyihao make the final." Xuan Jian:. "So, good also day both his daughter to light the way, and so long have smart reputation and to the good name of the final is it too long. "' Ling end "," to make the final, "the meaning of hospice represents.

\section{Summary}

Throughout Zhou inscriptions terminology, we can see the beginning of the Zhou Dynasty is not the pursuit of longevity. But this final wishes can not be achieved, with the accumulation of a gradual increase in the level of civilization and long-term life experiences, Zhou people begin to have a rational concept of life and death, people began to understand the illness and death of the inevitable, and thus able to obtain longevity happy and healthy prayer life, come to an end. From this we can see that a week is a positive and pragmatic nation nation. However, substantive content point of view, the concept of life and death Zhou people 's destiny with another color. From the outset showed longevity eternal pursuit and desire, but they agree with another form of the continuation of life - the gods, the dead ancestors bless generations from the scourge of the gods, get well-being. They pray to the ancestral spirits destiny forever, Ankang hospice, indicating their view that the ancestral spirits are capable of and protect them from this level, the Zhou Dynasty conception of death is actually a concept of destiny, is a conditional destiny theology.

\section{REFERENCE:}


[1] Yin Zhou Dynasty integration. Chinese Academy of Social Sciences Institute of Archaeology. Beijing Zhonghua Book Company, 2007. As used herein, the information are from the inscription "Yin Zhou Dynasty integration."

[2] Xu Shu. "Bronze Gu Shi speech cases." From "Xu Shu history paper selections', Zhonghua Book Company, 1998, 536.

[3] Xu Shu. "Bronze Gu Shi speech cases." From "Xu Shu history paper selections', Zhonghua Book Company, 1998, 536.

[4] Dai Jiaxiang "Bronze big dictionary under" that: "Paul is Li of semantic word plus side, before Han Kim resigned as Li stone, handed down by word transmission rate with Paul, Paul Li synonymous." Academia Press, 1999, 5104.

[5] Xu Shu "Bronze Gu speech interpretation cases" that: "Li classic pass for Paul," Poems "and many more Fluke said, adding that while the inscriptions are not," said the text "to release Paul blessing, a blessing to all the happiness the general, so Paul was release a blessing. this pass righteousness. Analysis of words, the original meaning of Paul, when the salary. "see," Xu Shu history paper selections', Zhonghua Book Company, 1998, 547. 